\title{
ON THE CHALLENGES OF THE USE AND INTEGRATION OF RENEWABLE ENERGY SOURCES
}

\author{
Mariano Martín \\ Department of Chemical Engineering, \\ University of Salamanca, Plz. Caídos 1-5, 37008, Salamanca, Spain
}

Overview: Although renewable energy sources are plentiful, their availability is highly volatile in time and distributed across regions while and the processes that transform them into useful power or chemicals are underdeveloped. In this work we discuss on the scope for the use and integration of renewable energy sources and the future development of the alternatives.

Energy, the sources and their availability, is one of the major concerns of today's society. Over the last decades fossil fuels, carbon from the 1920's and crude oil after 1970's, have been widely used due to their easy handling and transformation into liquid fuels or electricity. However, the distribution and limited availability of fossil energy sources have come into the picture with the increase in the world's energy consumption (Siirola, 2014). Thus, there is a need for more efficient systems and the use of additional sources of energy to maintain the current standards of living. Furthermore, sustainability issues have spread across sectors as a result of the awareness of our current society. Regarding the energy sector, there is an increased support for the use of renewable sources and the development of efficient processes to transform them into handy forms of energy and fuels. Nonetheless, the production of energy comes together with a large consumption of water which has become another important challenge.

However, there are a number of challenges associated with the use of renewable sources, due to their local and temporal availability. Among the renewable energy sources we distinguish two groups: Those whose availability can somehow be regulated-such as biomass, waterfalls and geothermal and those whose availability is highly volatile- wind and solar energy. If we start commenting about the first group, biomass is actually the way nature stores solar energy. It can be a source of food, energy or building materials. Biomass is produced at certain times of the year; it can be stored for a period of time and transformed. Biomass transformation processes are being designed to produce electricity or liquid fuels, mainly bioethanol or biodiesel but also more advanced fuels such as synthetic gasoline and diesel (Fischer Tropsch) (Swanson et al., 2010), glycerol ethers (Martín and Grossmann, 2014) or DME (Ohno, 2002) which can substitute crude based gasoline and diesel. The first generation of biofuels used corn, wheat, rapeedseed or soy to produce bioethanol or biodiesel, presented an ethical dilemma: The use of biomass to produce energy instead of food. As a result, the food prices of certain basics rose. The development of second and further generations of biofuels aimed to break the link between food and energy production from biomass since the energy crops do not use agricultural area nor the products can be used as food. The second objective of later biofuel generations was to increase the production capacity of alternative fuels. However, the production costs of biofuels are still not yet competitive with those of crude based gasoline or diesel and thus the possibility of simultaneously producing high added value products and fuels has been proved to be a way to improve the economics of biorefineries and diversify the product portfolio. Furthermore, the area availability for biomass production is a critical issue as well as water consumption for biomass growing and processing (Martín and Grossmann, 2013). Hydropower production is controlled with dams for short time horizons, while the regional rain determines the actual availability in the medium term. Therefore, it is possible to somehow control the production over short periods of time. In case of an excess of energy at certain times, water is pumped up so as to use the energy later. However, it can be more difficult to ensure a certain production capacity over seasons (DOE, 2013). Geothermal energy depends on the temperature of certain layers of the Earth, which is typically within a specific range. However, only a small fraction can be exploited due to technical and economic factors (NREL, 2014). On the other hand, wind and solar 
energy are more complex sources. Widely spread across the globe, their availability is not only regional dependent, but also temporal. The engineered way to capture wind and solar energy has some drawbacks. Wind is typically used to generate electricity using wind turbines whose design is currently being improved. Regarding solar, apart from its use to grow biomass and to heat water, it is being captured to produce electricity either through Photovoltaic Panels (PV), or concentrated to generate steam that is used to produce electricity, know as Concentrated Solar Power (CSP). However, the production of electricity out of solar and wind energy during a day or during a year is not constant and thus meeting a certain demand is a real challenge.

With this mix of sources of renewable energy, one stands at the crossroads as how competitive they are and they can become, which one to select and develop, based on economic, social and environmental criteria and how to combine or use them. It is important to notice that the use of renewable energy has some decades of delay in development compared to fossil fuels, even though it has been used for centuries. Therefore there is a large scope for research in a number of fields. Furthermore, the advances in materials, catalysts, process design and integration, with the idea of optimizing the petrol industry, also benefit, make possible and improve the use of renewable sources of energy. The decision of pursuing the use of each one has to be also local or regional. Area and water availability comes also into play due to the needs for growing biomass, for solar panels allocation or dam's construction and water availability, not only for biomass growth, but also as utility within the transformation processes. One interesting question is who has to fund the development and implementation of renewable energy, private or public bodies. The competitive energy markets of either fuels or electricity make it really difficult for an alternative source to enter without help. That "help" does not only mean an investment and technical improvement, but also the social awareness for the need of a sustainable development and the currently more supported policy to go sustainable, that typically results in passing laws in favor of renewable resources. Therefore, the governments must provide the grounds for including a more sustainable way for producing energy into the actual market, due to the large investments needed and the status of lower development in comparison with fossil fuel energy, but in the end private companies should take the lead so that competence improves the prices and offer of energy sources. Finally, in order to meet a certain demand, integration of resources at local (Martín and Grossmann,
2014) or greater scale (Cucek et al., 2014), has become an interesting engineering and technical challenge. There are some options to deal with this problem. An alternative is the combination of a number of energy sources so that we can cope with the demand when solar or wind energy cannot provide it, see figure 1 in ref. (Yuan and Chen, 2012). Unit commitment problem is being around for some time and can address the issue in a regulated network, while process integration can be an option at local level. Another option is to use that electricity and produce chemicals. As well as when they are produced from biomass, the advantage of producing liquid fuels and/or chemicals is the possibility of building a stock and, thus storing renewable energy in a handy form. Through electrolysis, hydrogen is produced and can be further used as fuel or to obtain ammonia, methanol, methane. Renewable hydrogen also allows $\mathrm{CO}_{2}$ capture, since it can be the carbon source to produce chemicals (Davis and Martín, 2014; Van-Dal and Bouallou, 2013). Electricity storage in batteries is still very limited and presents a major technical challenge (Gençer et al., 2014). In order to help with those decisions, process system engineering has the tools to compare sources and allocations in search for the optimal options at local and wider scales.

\section{REFERENCES}

Cucek, L., M. Martín, I.E. Grossmann and Z. Kravanja, 2014. Large-scale biorefinery supply network-case study of the European Union. Comp. Aid. Chem. Eng., 33: 319-324. DOI: 10.1016/B978-0-44463456-6.50054-5

Davis, W. and M. Martín, 2014. Optimal year-round operation for methane production from $\mathrm{CO}_{2}$ and Water using wind and/or solar energy. J. Cleaner Prod., 80: 252-261. DOI: 10.1016/j.jclepro.2014.05.077

DOE, 2013. Hydropower technology basis. http://energy.gov/eere/energybasics/articles/hydropo wer-technology-basics

Gençer, E., E. Al-Musleh, D.S. Mallapragada and R. Agrawal, 2014. Uninterrupted renewable power through chemical storage cycles. Current Op. Chem. Eng., 5: 29-36. DOI: 10.1016/j.coche.2014.04.001

Martín, M. and I.E. Grossmann, 2013. On the systematic synthesis of sustainable biorefineries Ind. Eng. Chem. Res., 52: 3044-3064. DOI: 10.1021/ie2030213 
Martín, M. and I.E. Grossmann, 2014. Simultaneous optimization and heat integration for the coproduction of diesel substitutes: Biodiesel (FAME and FAEE) and glycerol ethers from algae oil. Ind. Eng. Chem. Res., 53: 11371-11383. DOI: 10.1021/ie402443t

NREL, 2014. Geothermal energy basis. http://www.nrel.gov/learning/re_geothermal.html

Ohno, Y., 2002. Japan DME Forum Workshop, Tokyo, pp: 113-122.

Siirola, J.J., 2014. Speculations on global energy demand and supply going forward. Current. Op. Chem. Eng. 5, 96-100. DOI: 10.1016/j.coche.2014.07.002
Swanson, R.M., A. Platon, J.A. Satrio and R.C. Brown, 2010. Techno-economic analysis of biomass-toliquids production based on gasification. Fuel, 89: S11-S19. DOI: 10.1016/j.fuel.2010.07.027

Van-Dal., E.S. and C. Bouallou, 2013. Design and simulation of a methanol production plant from $\mathrm{Co} 3$ hydrogenation. J. Cleaner Prod., 57: 38-45. DOI: 10.1016/j.jclepro.2013.06.008

Yuan, Z. and B. Chen, 2012. Process synthesis for addressing the sustainable energy systems and environmental issues. AIChE J., 58: 3370-3389. DOI: 10.1002/aic.13914 